\title{
Research on the Dissemination and Response of Network Public Opinion of Emergency Events in Colleges Based on Crowd Intelligence Thinking
}

\author{
Peng Cui, Yi He* \\ Central University of Finance and Economics, Beijing, China \\ Email: heyi@cufe.edu.cn
}

How to cite this paper: Cui, P. and He, Y. (2019) Research on the Dissemination and Response of Network Public Opinion of Emergency Events in Colleges Based on Crowd Intelligence Thinking. Open Journal of Social Sciences, 7, 281-290.

https://doi.org/10.4236/jss.2019.710023

Received: January 8, 2019

Accepted: June 6, 2019

Published: October 23, 2019

Copyright $\odot 2019$ by author(s) and Scientific Research Publishing Inc. This work is licensed under the Creative Commons Attribution International License (CC BY 4.0).

http://creativecommons.org/licenses/by/4.0/

\begin{abstract}
The phenomenon of Crowd intelligence among college student groups has formed a Crowd intelligence network of college student edition through the Internet. The problem of network public opinion of college emergencies in the Crowd intelligence network has gradually become a hot topic for scholars to study. In view of this, this paper analyzes the challenges and existing problems of the network robustness of colleges in the Crowd intelligence network facing the network public opinion of emergencies. With the help of the life cycle theory in crisis management, the dissemination law of network public opinion of emergencies in colleges is studied, the development life cycle of network public opinion on emergencies in colleges is constructed by gestation period, outbreak period, diffusion period, repetition period, extinction period and long-tail period, and corresponding solutions are proposed for each period.
\end{abstract}

\section{Keywords}

Crowd Intelligence, Colleges, Network Public Opinion, Solutions

\section{Introduction}

The phenomenon of Crowd intelligence widely exists in politics, economy, humanities and other fields. With the development of Internet, the phenomenon of Crowd intelligence gradually presents a networked Crowd intelligence type economic and social form of internet of everything. As the main form of the mod- 
ern service industry and the future economic society, the related research of the Crowd intelligence network can promote the government governance activities to be more effective and more humanized, so as to avoid the possible chaos, turbulence and abrupt change to the greatest extent. However, in colleges and universities as a microcosm of society, the phenomenon of Crowd intelligence among college student groups has formed a Crowd intelligence network of college student edition through the Internet. The problem of network public opinion of college emergencies in the Crowd intelligence network is related to the fluctuation of college students' thoughts and emotions, and the security and stability of the campus has gradually become a hot pot of research for scholars.

College students have a strong ability to accept new things and are willing to accept new things, but they lack the ability to identify them. Especially under the stimulus of wrong ideological trends, they are very easy to lose their ideals and beliefs, choose the wrong value orientation, and confuse their way of life. Therefore, this paper will base on Crowd intelligence thinking and make use of the mass flow shock of public opinion data on the college network robustness in Crowd intelligence network, so that the normal operation of the network system of colleges can be guaranteed, and the students' emotions mapped by the network can be responded in the first time, accurately and comprehensively exposed to the public and handled efficiently. Thus, the network public opinion of college emergencies can be reduced from the point of explosion to the point of calming down, thus improving the credibility of the school.

\section{Challenges Faced by Colleges in Dealing with Network Public Opinions of Emergencies}

With the exposure of more and more public events in colleges and universities, colleges and universities are also involved in the whirlpool of public opinion. An urgent problem to study and solve is how to deal with them under the supervision of public opinion. If the network public opinion is not handled properly, the pressure of public opinion will soon upgrade and worsen the situation, which will not only lose the confidence of students, but also directly affect the image of the school. Therefore, in the changing environment of network public opinion, it is particularly important for schools to take timely and effective response measures [1].

\section{1) Scale expansion of netizen}

On the one hand, the social status of Chinese netizens is relatively low, which can be reflected from the professional level. Students and individual households/freelancers have the highest proportion in the total number of netizens in China, respectively. The proportion of unemployed/laid-off/jobless persons in the total number of netizens in China has declined, but it is second only to students, individual households/freelancers. On the other hand, the group polarization effect of Chinese netizens is obvious, and shows a trend of strengthening. In recent years' emergencies, netizens are increasingly influenced by the opinions of other members, and even become more extreme, emotional and irrational. If 
this irrational expression is allowed to spread and develop, it will depress the rational voice and confuse the dissemination of public opinion, resulting in the expansion of events and seriously affecting the rational development of events and positive response.

\section{2) Activation of network public opinion orientation}

Chinese netizens' comments on various emergencies have reached an unprecedented level of activity, especially some emergencies with greater impact with strong comments in the new network media. These influential public opinions have brought strong social pressure to the governance of schools. If schools cannot effectively control these inappropriate speech and malicious incitement, it will eventually lead to more unscrupulous behavior of students' netizens in the new network media, the virtual network society will be more chaotic, and students' netizens themselves will suffer from it.

\section{3) Pluralism of public values}

The rapid development of social economy and the growing differentiation of interest groups will inevitably lead to a large number of social contradictions and emergencies. Therefore, when the emergencies occur, the development of public opinion can see the expression of various extreme emotions of students' netizens, especially the messages and news comments in the online world. Many students' netizens are very easy to follow the trend impulsively without any clear reasons. From the perspective of the school, the student netizens' right to speak on the Internet also has two effects on the management and authority of the school in the development and dissemination process of network public opinions. On the one hand, the public opinion provides a convenient channel and method to enable the school to quickly understand the public sentiment and opinion. On the other hand, with the increase of information and the blindness of comments, it is easy to cause the unreasonable student netizen to cause the campus disorder.

\section{4) Diversification of the public opinion field}

In the past, traditional media has always been the patent of news editors, journalists and some media organizations. Today, the public is the producer and disseminator of media, which has truly realized the communication mode of "public participation, instant sharing". Nowadays, the large amount of information in various forms of network new media cannot be fully understood, resulting in the emergence of personalized fast-food reading, which will cause the mileage and credibility of network news reports to be further implemented. How to improve the ability of schools to deal with emergencies on the network with relatively weak social control mechanism will be an important issue.

\section{The Problems of Colleges in Dealing with Network Public Opinion of Emergencies}

With the development and popularization of the network, the public is paying more and more attention to the network public opinion. Schools also pay close attention to network public opinion, and the quality of school response from the perspective of network public opinion is gradually improving. However, the net- 
work public opinion of emergencies also has the characteristics of concealment, instantaneity and suddenness, which will make schools lag behind and imperfect in dealing with emergencies [2].

\section{1) Low ability to respond in time}

With the rapid development of the network, "golden 24 hours" cannot meet the needs of the present era. Therefore, some public opinion research institutions put forward the "golden 4 hours" principle, and even some institutions put forward the "golden 1 hour" principle [3]. The increasingly frequent crisis of network public opinion has tested the school's response ability and posed a severe challenge to the image building of the school. The traditional coping modes are mainly manifested in inaction, lagging reaction, passive perfunctory, blockade and retaliation, which have seriously damaged and destroyed the school image. With the rapid development of the Internet, the awareness of protecting public rights and interests has become mature, requiring schools to respond in the first time.

\section{2) Low level of information disclosure}

For such types of events as information opacity, system absence and inaction, and information disclosure and dialogue can enhance mutual understanding [4], while analysis and decision-making can resolve contradictions, thus fundamentally preventing or calming events [5]. Silent or contemptuous attitude will give up an effective way to actively understand people's feelings and opinions, leading to unfavorable public opinion. If schools want to deal with emergencies efficiently and quickly, they should timely understand student netizens' ideas and communicate with them in time. However, there are still many schools still cannot clearly understand the principle, and in the face of public opinion crisis, the first step they take is to delete posts to block public opinion. Network public opinion response is to convey open, transparent, real and effective information to the public and the media, so as to eliminate doubts and nip the public opinions in the bud.

\section{3) Weak management mechanism}

At present, our colleges and universities have not yet established a set of scientific and effective mechanism for collecting, researching and utilizing network public opinion. Their ability of public opinion research and judgment is weak. They cannot find out the network public opinion in time to prevent it from happening, and their ways of dealing with the network public opinion are simple and crude. They often adopt the ways of closing, blocking, deleting, dragging and concealing to deal with the network public opinion, which is not only impossible to resolve contradictions in time, but also may even lead to further intensification of contradictions [6]. In the face of the network public opinion, the crisis monitoring system has not been established, and the crisis plan is unreasonable and standardized. In the face of the network public opinion, schools tend to be in a passive situation. In many cases, the relevant departments begin to respond only when the public opinion has entered a crisis state. 


\section{Network Public Opinion Dissemination Stage of Emergency Events in Colleges and Universities Based on Crowd Intelligence Thinking}

Network public opinion of college emergencies is the political attitude, beliefs and values that students netizens convey through network media in response to emergencies in a specific social environment. Its essence is to gather, share and exchange incident-related information among relevant departments of schoolstudents-netizens-network media around emergencies. Therefore, the network public opinion of emergencies has the general characteristics of information ecosystem. Scholars at home and abroad have carried out a large number of case studies, and summed up the stage of network public opinion dissemination of emergencies. The representative ideas are three-stage theory [7], four-stage theory and five-stage theory [8], and some scholars have put forward multi-stage theory. The division of existing public opinion stages of public emergencies is sorted out and summarize as shown in Table 1.

Network public opinion on college emergencies is mainly expressed by posting and commenting through "two microblogs, one blog" and forums, which has the characteristics of interaction and instantaneity. For the study of the life cycle of network public opinion on college emergencies, this paper makes a statistical analysis of the attention data such as the number of articles posted and the number of replies to specific network public opinion on specific college emergencies in order to verify the periodic law of network public opinion in college emergencies.

Different scholars have different research perspectives and methods. The development stage and stage division of network public opinion of emergencies are uncertain. From the previous case analysis, we can see that emergencies form a complete life cycle from generation to extinction. This process is similar to the life course of organisms, but also needs to experience the process of birth, growth, maturity and aging. Therefore, based on the theory of crisis stage analysis, this paper divides the network public opinion of college emergencies into six different stages: brewing period, outbreak period, diffusion period, repetition period, recession period and long tail period.

\section{Measures for Colleges and Universities to Deal with Network Public Opinion on Emergencies under the Background of Crowd Intelligence Thinking}

College emergencies are easy to get the attention of student netizens and the media, especially the major emergencies related to the interests of students' netizens. Public opinion attention will increase sharply in a short time. Every move of the school is in the spotlight of public opinion, and it quickly becomes a public hot spot. At this time, if the incident is not handled reasonably in time, public opinion will boost the tide, making the school itself into a whirlpool of public opinion, seriously damaging the image and credibility of the school. Therefore, 
Table 1. A summary of the research on the evolution stages of network public opinion in University Emergencies Based on Crowd intelligence thinking.

\begin{tabular}{|c|c|c|c|c|}
\hline Scholars & Research objects & Stage classification & Stage types & Basis for classification \\
\hline Wang Laihua & Network public opinion & Generation $\rightarrow$ Diffusion $\rightarrow$ Recession & & 1 \\
\hline Chen Yuesheng & $\begin{array}{l}\text { Network public opinion of } \\
\text { emergencies }\end{array}$ & Generation $\rightarrow$ Diffusion $\rightarrow$ Recession & & I \\
\hline Shi Bo & $\begin{array}{l}\text { Network public opinion of } \\
\text { Public Crisis }\end{array}$ & $\begin{array}{l}\text { Generation } \rightarrow \text { Development (Action/variation) } \rightarrow \\
\text { End }\end{array}$ & 3 stages & l \\
\hline $\mathrm{Xu}$ Jinghong & $\begin{array}{l}\text { Network public opinion } \\
\text { on unconventional } \\
\text { emergencies }\end{array}$ & Generation $\rightarrow$ Dissemination $\rightarrow$ Aggregation & & Life cycle theory \\
\hline Fang Fujian & Network public opinion & Inoculation $\rightarrow$ Diffusion $\rightarrow$ Change $\rightarrow$ Recession & & Life cycle theory \\
\hline Liu Yi & Network public opinion & $\begin{array}{l}\text { Fluctuation } \rightarrow \text { Sequential change } \rightarrow \text { Conflict } \rightarrow \\
\text { Recession }\end{array}$ & & I \\
\hline Jiang Shenghong & $\begin{array}{l}\text { Network public opinion } \\
\text { hotspots }\end{array}$ & $\begin{array}{l}\text { Initiation } \rightarrow \text { Sustainable development } \rightarrow \text { Fluctuated } \\
\text { diffusion } \rightarrow \text { Recession and desalination }\end{array}$ & 4 stages & $\begin{array}{l}\text { The development of the } \\
\text { event itself, netizens' } \\
\text { emotions and other factors }\end{array}$ \\
\hline Cao Jinsong & Network public opinion & $\begin{array}{l}\text { Dissemination } \rightarrow \text { Aggregation } \rightarrow \text { Heated discussion } \rightarrow \\
\text { Popularization }\end{array}$ & & I \\
\hline Wang Kequn & $\begin{array}{l}\text { Interaction of network public } \\
\text { opinion with real society }\end{array}$ & Generation $\rightarrow$ Rise $\rightarrow$ Fluctuation $\rightarrow$ Recession & & I \\
\hline Yu Lian & Network public opinion & $\begin{array}{l}\text { Gestation } \rightarrow \text { Outbreak } \rightarrow \text { Spread } \rightarrow \text { Transition } \rightarrow \\
\text { Dormancy }\end{array}$ & & Life cycle theory \\
\hline Xie Kefan & Network public opinion & $\begin{array}{l}\text { Incubation } \rightarrow \text { Germination } \rightarrow \text { Acceleration } \rightarrow \\
\text { Maturity } \rightarrow \text { Recession }\end{array}$ & 5 stages & Life cycle theory \\
\hline Gu Mingyi & Network information & $\begin{array}{l}\text { Early dissemination } \rightarrow \text { Social informed period } \rightarrow \\
\text { Social expression period } \rightarrow \text { Social action period } \rightarrow \\
\text { Media memorial period }\end{array}$ & & $\begin{array}{l}\text { The participatory } \\
\text { experience theory in the } \\
\text { frontier of communication } \\
\text { science }\end{array}$ \\
\hline Ma Yinghong & Network public opinion & $\begin{array}{l}\text { Issue occurrence } \rightarrow \text { Information loss } \rightarrow \\
\text { Information search } \rightarrow \text { Public opinion formation } \rightarrow \\
\text { Public opinion guidance } \rightarrow \text { Public opinion decline }\end{array}$ & 6 stages & l \\
\hline Yu Guoming & Public opinion hotspots & $\begin{array}{l}\text { Incident occurrence } \rightarrow \text { Internet disclosure } \rightarrow \\
\text { Traditional media reporting } \rightarrow \\
\text { Internet media sensationalization } \rightarrow \\
\text { Impose pressure by public opinion } \rightarrow \\
\text { Intervention } \rightarrow \text { Appeasing of public opinion }\end{array}$ & 7 stages & / \\
\hline
\end{tabular}

this paper puts forward the corresponding measures from six stages: brewing period, outbreak period, diffusion period, repetition period, recession period and long-term tail period.

\section{1) Brewing period}

When the development of events is in the brewing period of the life cycle of network public opinion, opportunities outweigh threats. In this period, students' netizens only express their opinions, attitudes and emotions by posting, follow- 
ing up and reposting online. Therefore, it should be the responsibility of the professional network public opinion monitoring institutions of schools to collect and sort out the network information, and closely monitor and pay attention to the development of the public opinions by relying on the modern information technology and network. At the same time, they should build a network communication platform to protect students' right to know, curb the spread of false information, attach importance to data mining, improve monitoring means, know the evolution law of network public opinion, and formulate reasonable solutions.

a) Focus on student netizens' forum posting. As the main college emergencies that easily attract the attention of students are the public opinion hotpot events in aspects of teachers' ethics, academic misconduct and improper speech, the monitoring agencies should monitor sensitive topics and words in these events to prevent the spread of false information and affect the handling of emergencies. Once the school has mastered the information, it should transmit it in time and at the fastest speed, so as to avoid the dissemination of some false information, help to occupy the commanding heights of public opinion, and obtain the initiative of public opinion response.

b) Pay attention to the emotional attitude of students' netizens. The school network public opinion monitoring organization should observe the student netizens' emotional attitude towards the network public opinion. The opinions of netizens have not yet formed in the brewing period. At this time, most of the posts or comments are the vent of discontent. Therefore, the school network public opinion monitoring organization should observe the intensity of the words used in the posts or comments. Once the words are found to be intense, it indicates that the incident may lead to the fermentation of public opinion. It is necessary to inform the relevant departments concerned and report the problems to the school leaders promptly so as to put forward the response plan as soon as possible and resolve the public opinions in time.

\section{2) Outbreak period}

During the outbreak period of network public opinion, schools are facing a greater threat mainly from students' questioning of the incident, and it is very likely that they will make wrong judgments on the hearsay news and publish and disseminate some false news. The school shall respond to and dominate the trend of public opinion. Their speed and attitude of resolving emergencies determine the duration of the outbreak of network public opinion. At the same time, the effectiveness and timeliness of the school response, the transparency of the handling process and the fairness of the handling results will directly determine the students' satisfaction with the handling of the incident.

a) The subject of the response should be clear. Colleges and universities have basically established a news spokesman system, which has played a very good role in responding to emergencies, but students' netizens pay more attention to the attitudes and measures of the subjects or parties involved. If it is only the 
spokesperson who comes out to clarify the facts, students' netizens will have a sense of perfunctory prevarication and shirking responsibility. Therefore, when the school responds, the subjects and parties concerned should also be present to show their attitude in addition to the spokesperson's response to the incident, so as to reduce the pressure of public opinion.

b) The response should be made timely. Schools should show their attitude and position at the first time of the incident. Whether the response is timely or not largely determines the duration of public opinion [9]. The quicker the response, the sooner the scope and influence of public opinion can be controlled. If the facts of the incident have not been confirmed, the opinions and process of handling should be expressed in a timely manner. If this step is completed well, the network public opinion of the event will be moderated and controlled to a certain extent.

c) The altitude of response should be sincere. In order to get the recognition of students' netizens, attitude must be sincere. If the fault is obvious, then we must dare to assume responsibility without shirking and evading [10], so as to pull in the distance of students' netizens and reduce students' discontent to a certain extent. At the same time, when responding to the network public opinion, we should pay attention to the speech and behavior, and must not use the fuzzy words which cannot convey our ideas correctly or speak stereotyped in form. We must speak the truth to make the public understand. At this time, the better way of response is to let the news spokesman publish the unified information.

\section{3) Diffusion period}

The credibility of schools involved in public opinion incidents in the diffusion period has been greatly questioned, and the public has reached a fairly high degree of questioning. Schools should stand up decisively and make public and impartial responses by holding press conferences as respondents to the public. In addition, the speaker should popularize professional knowledge, timely understand and master the basic knowledge related to events, and be able to quickly adjust his position and methods with the progress of events, the transfer of contradictions, the fermentation of public opinion and the breeding of rumors. Students' netizens will not strongly question the information control, professional level, media literacy and public opinion response ability of news spokespersons.

\section{4) Repetition period}

During this period, the incidence of network rumors and students' public opinion is relatively high, students' netizens' attention has been quite extensive, and the situation of the incident is also quite well understood. Schools should communicate with the involved parties quickly, compress the time and space of rumor dissemination, speed up the response speed, and publish authoritative information. Otherwise, once rumors spread, students who do not know the truth will be more easily encouraged and cause greater riots. At the same time, the parties involved in the events should have a proper attitude and face the que- 
ries and criticisms of netizens correctly. If it is a mistake of themselves, they should be generous to face criticism and criticism from netizens, apologize publicly, and make prompt corrections; if their own practice is correct and netizens misunderstand or question their practice, they should find out the relevant basis and publicly indicate the reasonableness of the practice.

\section{5) Recession period}

In order to avoid the recurrence of such emergencies, the departments involved in schools should summarize and reflect on the incidents, find out the deficiencies and shortcomings in their daily work, revise the corresponding system in combination with the media or the public's deep reflection on events during the recession, and standardize the behavior that causes public opinion, so as to avoid similar mistakes in their work in the future. At the same time, the school departments involved in the events shall repair their own image. If the image and credibility of the school are affected, or when public opinion erupts, it causes more serious image damage or loss of credibility because of inappropriate response, and then the school should also try to restore the image through the media to enhance its credibility.

\section{6) Long-term tail period}

Schools should deal with the relationship with the public and the media well, accept the supervision and criticism of the public and the media actively, satisfy the public's right to know and speak, properly handle the relationship among the school, the media and the public, reshape the image of the school and respond to the public's demands. Schools should improve the supervision mechanism, pay attention to improving the quality of managers, strengthen self-examination and self-supervision, and guard against hidden dangers. In addition, school network monitoring organization cannot relax the monitoring of crisis events, but should continue to observe, in order to prevent the recurrence of the crisis caused by rumors or unexpected factors, and prevent its resurgence.

\section{Conclusion}

Studies have shown that, the development life cycle of network public opinion on emergencies in colleges is constructed by gestation period, outbreak period, diffusion period, repetition period, extinction period and long-tail period, and corresponding solutions are proposed for each period.

\section{Funding}

This paper is a phased achievement of the key project of the National Social Science Foundation, "Research on the impact of information network technology on market-determined resource allocation" (No. 14AZD118).

\section{Author's Brief Introduction}

Cui is Associate Professor from the Office of Discipline Inspection Commission at Central University of Finance and Economics, Research Field: Educational 
Management; He is Assistant Professor from the China Center for Internet Economy Research at Central University of Finance and Economics, Research Field: Educational Management.

\section{Conflicts of Interest}

The authors declare no conflicts of interest regarding the publication of this paper.

\section{References}

[1] Zhao, L.G. and Yang, Q. (2018) Research on the Management Mechanism of Response to Network Public Opinion Caused by College Emergencies. The Guide of Science \& Education, 12, 14-15.

[2] Ma, Y.H. (2010) Thoughts on the Basic Characteristics of Network Public Opinion. Theory Research, 18, 124-125.

[3] Pu, H.G. (2015) Public Opinion Response Enters the Era of "Golden 1 Hour". News Front, 21, 108-109.

[4] Fang, R. (2013) Study on the Mechanism of the Government Education Department to Deal with Mass Incidents Caused by Online Public Opinions in Colleges and Universities. Electronic Government, 2, 40-48.

[5] Li, P. (2010) Research on Online Public Opinion Response Mechanism of Local Governments. Journal of Shanxi Administration School and Shaanxi Economic Management School, 2, 55-57.

[6] Bao, X.J., Xie, T.Y. and Liu, L.Y. (2019) Research of the Response to Network Public Opinion of Emergencies in Colleges and Universities. University Logistics Research, 6, 68-70.

[7] Wang, L.H. (2005) On the Changing Law of Public Opinion. Academic Exchanges, 12, 155-159.

[8] Jang, S.H. (2010) Study on the Formation and Development of Network Public Opinion. Lanzhou Academic Journal, 5, 77-79.

[9] Li, T.L. (2017) Analysis on the Response Strategy of College Network Public Opinion Events. Reform \& Openning, 5, 62-64.

[10] Wang, L.P. (2016) Diagnosis and Intervention of Online Public Opinion in Colleges and Universities from Psychological Perspective. Journal of Chengdu Electromechanical College, 2, 19. 